\title{
FLORES DE RETÓRICA EN EL PRIMUS CALAMUS DE JUAN CARAMUEL Y LOBKOWITZ
}

\author{
ANDREA BALDISSERA \\ Università del Piemonte Orientale, Italia
}

\section{CARAMUel y La Retórica}

Leer obras de Juan Caramuel significa enfrentarse a menudo a enciclopedias de tipo especial, pequeños mundos que tratan de abarcar lo conocible en sus innumerables facetas y sobre todo en sus infinitas relaciones. Como era de esperar, en varias de estas recopilaciones, la retórica forma parte del conjunto de ciencias y disciplinas mencionadas y analizadas. La misma definición de retórica vuelve a ofrecerse más de una vez, según puntos de vista diferentes: si en el Apparatus Philosophicus Caramuel proporciona una clasificación de las artes y una descripción de la retórica basada en un símil situado dentro del ámbito del trivium («Rhetorica est grammatica elegans, nec 
potest carere dialectica $»^{1}$ ), en la Metalogica completa el discurso, al aclarar las relaciones que aquélla guarda con la lógica:

Quintilianus libro II Oratoriarum Institutionum duo esse orationis genera docet: altera enim oratio est perpetua, \& rhetorica; altera concisa \& dialectica dicitur: aitque has ita a Zenone conjunctas, ut hanc compressae in pugnum manui, illam explicitae diceret similem. Ergo, si stemus huic censurae, sicut aperta \& clausa manus in substantia non differunt, sic etiam rhetorica \& dialectica. Dicam igitur rhetoricam uberiorem \& copiosiorem logicam: \& logicam esse rethoricam concisam \& brevem ${ }^{2}$.

En el mismo Apparatus ${ }^{3}$ Caramuel añade una tabla explicativa donde se atribuye a la retórica -que actúa a nivel del sermo (junto a Gramática y Lógica)- la función de coordinar los elementos básicos, pertenecientes al nivel de la articulatio (Ortografía, Métrica, Rítmica, etcétera). En este mismo esquema, la retórica aparece también como una de las artes que preside al uso de los miembros del cuerpo, en cuanto forma de $a_{c t i o}{ }^{4}$. Finalmente, no menos interesante es la comparación que Caramuel pone, en la Encyclopedia Concionatoria, entre la elocuencia (y cada una de las partes: exordium, narratio, confirmatio, memoria y pronuntiatio) y la sangre cristiana derramada por la fe:

Eloquens est sanguis christianus pro fide catholica effusus; \& qui orationis partes exordium, narratio, confirmatio, memoria, \& pronuntiatio sunt, omnia haec sanguis innocens facit. Adorat Deum, orat ad Deum, dat novae foelicitati exordium, etiam tacitus gesta \& gerenda enarrat, constantiam singulorum confirmat, memoriam Dei concitat, \& contra iudicum crudelitatem ultimam sententiam pronuntiat ${ }^{5}$.

\footnotetext{
1 Juan Caramuel y Lobkowitz, Apparatus Philosophicus, Coloniae, sumptibus Joannis Arnoldi Cholini, 1665, Liber proœmialis, Disputatio I, p. 2. Pero en el mismo texto se ofrecen más definiciones. Por ejemplo: «Rhetorica. Et ipso foro \& templo servit, nam \& iurisperiti resolutiones suas persuadere conantur, \& concionatores persuadere virtutes» (Disputatio II, p. 8 -la disciplina se analiza en la p. 13-).

2 Juan Caramuel y Lobkowitz, Metalogica Disputationes de Logicae Essentia, Proprietatibus et Operationibus continens, Francofurti, sumptibus Joann. Godofredi Schônwetteri, 1654 (Liber I, Disputatio VI, Articulus IV, LXXX, p. 32).

3 Cf. Luis Robledo Estaire, «El cuerpo como discurso: retórica, predicación y comunicación no verbal en Caramuel», Criticón, 84-85 (2002), pp. 145-164.

4 «Et multa sunt facultates quae huc collimant. Rhetorica manuum motum et membrorum inclinationes competentes requirit; \& urbanitas invigilat serio regendis artubus. Consulto dicam serio; nam si iocos \& ludos respicimus, choreas, saltus, tripudia \& multa alia reperire solemus, quae constitunt in artuum artificioso motu, \& traduntur specialibus artibus» (Juan Caramuel y Lobkowitz, Apparatus, Liber proemialis, p. 2). Junto a música y teatro -según explica en el Trismegistus Theologicus- ésta es una de las manifestaciones del arte de la representación. Lo que supone la extensión del concepto tradiciónal de retórica a la gestualidad y corporeidad (cf. Luis Robledo Estaire, op. cit., pp. 149-150).

5 El texto prosigue así: «Tuus [i.e. sanguis], serenissime rex, tametsi purus \& innocens, nimis pretiosus est, ut pro fidelibus subditis effundatur; at Christi sanguis infinite preciosor, ac tamen non solum pro fidelibus sed pro infidelibus \& rebellibus fusus» (Juan Caramuel y Lobkowitz, Encyclopedia Concionatoria, Pragae, Typis Academicis, 1649, Oratio II, Articulus 21, p. 18). Es interesante notar, a este propósito, lo que hace el mismo Caramuel en una obrita publicada en Praga en 1652, dedicada a María y al símbolo del libro (antigua imagen presente en la oratoria y la espiritualidad occidental): María es libro de gramática, retórica, politica, ética, etcétera -quia omnia novit. Cf. Giovanni Pozzi, «Il libro in Caramuel», en S. Graciotti y J. Křesálková (eds.), Barocco in Italia. Barocco in Boemia. Uomini, idee e forme d'arte a confronto, Roma, Calamo, 2003, pp. 391-399.
} 
Por otro lado, es evidente que el uso de la retórica desempeña un papel fundamental en los textos del cisterciense ${ }^{6}$, ya que algunos de sus opositores le reprochan precisamente que abuse de argumentos retóricos en lugar de mantenerse agarrado a los hechos, o que sustituya la dialéctica por la retórica:

Desnuda pues de todo adorno, armada solo de la raçón se opone la justicia de nuestra causa a las frívolas y sofísticas repeticiones de Caramuel; porque no diga se vale de flores de retórica, quien tiene tan eficaces fundamentos en su abono $[\ldots]^{7}$.

Caramuel fraudem facit rhetoricae artibus, non oppugnat dialecticis syllogismis, \& armis. Nemo nostrum probabilitatem, \& probabiles opiniones damnat [... ${ }^{8}$.

\section{El Primus Calamus}

Entre las cerca de ochenta obras de la 'biblioteca de autor' de Caramuel ${ }^{9}$, una ha merecido el profundo interés de críticos y científicos por su especial condición de tratado poético-visual. Se trata del Primus Calamus, que retoma los juveniles intentos de trazar un viaje de exploración a través de gramática, métrica y rítmica ${ }^{10}$. Según es consabido, se articula en dos partes: la Metametrica (Romae, Fabius Falconius, 1663, en dos tomos), reservada a la exposición de los varios artificios formales útiles para producir mecánicamente textos poéticos; y la Rhytmica (Campaniae, ex officina episcopali, 1669), que expone la arquitectura de la métrica y rítmica.

La obra constituye una ars ingeniose poetandi, que explicita el sistema de reglas y recursos que actúan a ciertos niveles de la construcción lingüística y métrica: la combinatoria de piezas elementales o pertenecientes a las jerarquías bajas (letras y fonemas, sílabas y morfemas), pero también de lexemas, así como -obviamente- de versos y estrofas. En este texto se construyen, en efecto, máquinas para establecer todas las dispositiones poeticae posibles. Giovanni Pozzi así lo sintetizaba, al comentar el enfoque enciclopédico de Caramuel:

\footnotetext{
${ }_{6}^{6}$ Caramuel nunca fue predicador profesional o especialista de la predicación. Solo predicó en Lovaina (1643), en Baviera (1647) y en otras pocas ocasiones. Pero publicó también un manual de Quirología, sobre la técnica de usar las manos en discursos públicos.

7 Manuel Fernandes de Vila Real Anticaramuel o defença del manifiesto del reyno de Portugal, París, Miguel Blageart, 1643, pp. 236-237.

8 Juan de Cárdenas, Crisis theologica sive disputationes selectae ex morali theologia, Venetiis, apud Nicolaum Pezzana, 1693, Tractatus I, De probabilitate (Disputatio XV, Caput III, Articulus I), p. 199.

9 Cf. el estudio de Alfredo Serrai, Phoenix Europae. Juan Caramuel y Lobkowitz in prospettiva bibliografica, Milano, Sylvestre Bonnard, 2005.

10 De esta temprana tensión hacia el tema procede el nombre del texto: metafóricamente, el 'primer libro'. Recordemos que, al final de los dos tomos de la primera parte, Caramuel hace reseña de su opera omnia (Juan Caramuel y Lobkowitz, Metametrica, Romae, Fabius Falconius, 1663 fascículo *v) donde así afirma: «Primus Calamus. Est liber quem in pueritia scripsit, in adolescentia promovit, \& nunc in senectute elimat. Ejus tomi sunt tres: Primus Grammatica [...] Secundus Rhytmica [...] Tertius Metametrica».
} 
[...] donde l'interesse acuto per discipline apparentemente minori, come la metrica, che in una mente siffatta diventò infallibilmente metametrica cioè arte che, fondata sulla matematica, deve identificare schemi prosodici e ritmici astratti, i quali, una volta rivestiti di parole, possono moltiplicarsi in una quantità enorme di versi concreti $^{11}$.

Tal operación no se centra solamente en lo matemático, lo que es innegable, sino que está necesariamente basada en los predeterminados mecanismos conectivos y combinatorios de los varios idiomas. Son mecanismos que rechazan las simplificaciones de los algoritmos, y donde lo probabilístico o lo probable tienen que acoplarse a lo discursivo (es decir a morfología y sintaxis, lingüísticas y poéticas) y arrodillarse frente a los criterios de la sintagmática y de la paradigmática.

Por eso, si la tratación parte del nivel de la articulación (véase supra), pronto rebasa sus límites y llega al nivel del discurso. Claro está que todo esto no convierte al Primus Calamus en un opus rhetoricum, pero es verdad que el libro nos proporciona una serie de pasajes en los que se reconoce la atención hacia aspectos típicos del ars loquendi. Por ejemplo, participa de las tendencias retóricas de la modernidad, que van centrándose más y más en la elocutio y actio ${ }^{12}$. Por otro lado, logra tocar algunas cuerdas de sus lectores para movere esa especie de esprit de géométrie que a menudo despierta la admiración hacia ciertas clases de productos del ingenio humano (tablas, laberintos, etcétera). Así como consigue persuadir (suasio) de que, detrás de la ars combinatoria de los elementos lingüísticos, está la combinatoria del alfabeto de la creación divina.

Esto explica por qué Caramuel hace hincapié también en lo infinito de estas relaciones y añade cálculos matemáticos que dejen constancia de ello. El Padre Pozzi reconoce la tradicionalidad de tal comportamiento:

Se gli autori procederono con tanta caparbietà a trascriverne tutti gli esiti [...] non è per provare la giustezza del teorema $[. .$.$] bensì per sottoporre all'occhio il$ concetto dell' infinità cosmica che vi è implicito; poco importa quale sia il tenore del

11 Giovanni Pozzi, La parola dipinta, Adelphi, Milán, 1981, p. 243.

12 Cf. Elena Artaza, «Las retóricas barrocas (1600-1650). Notas introductorias», en E. Artaza et alii (eds.), Estudios de Filología y Retórica en Homenaje a Luisa López Grigera, Bilbao, Universidad de Deusto, 2000, pp. 45-66. Hay que recordar que en el enciclopedismo caramueliano, «le unità di ogni disciplina sarebbero interscambiabili e perciò l'enciclopedia si potrebbe facilmente dominare mediante il controllo delle combinazioni» (Giovanni Pozzi, ibidem). Véase Arturo Martone, «Juan Caramuel o dell'Ignegno metametrico», en S. Gensini y A. Martone (eds.), Ingenium propria hominis natura, Nápoles, Liguori, 2002, pp. 231-261: «[...] l'idea di una "autonomia del significante" potrà nondimento, anche nella Metametrica, aspirare a riguadagnare una sua credibilità, laddove venga inscritta in quel più complessivo processo che, inauguratosi in epoca umanistica, vede una lenta ma inequivocabile autonomia sul piano della elocutio ovvero dei "modi bene dicendi", nome classico dell'Ars rhetorica: un'autonomia in cui si traduce quel processo, inaugurato appunto sin dalla "neo-retorica" umanistica, di scorporamento e separazione della Elocutio appunto dalle altre quattro parti di organizzazione del discorso (Inventio, Compositio, Memoria, e Pronuntiatio). Autonomia che, nel caso della Metametrica, si paleserà nel programmatico disancoramento del significante dal piano del significato, purché tale disancoramento appaia guidato e finalizzato al perseguimento della "idea metrica" » (pp. 240-241). 
messaggio linguistico; questo infatti è spesso puramente occasionale usato tanto bene che male a fine encomiastico, sia religioso sia profano [...] certo a sottolineare che lo scopo verso del messaggio sta unicamente nella produttività del modulo. E non altra spiegazione ha l'insistere noioso e in apparenza ebete su calcoli fatui, per sapere in quanti secoli i risutati potrebbero essere trascritti o letti ${ }^{13}$.

En el Primus Calamus, de hecho, no se oculta la preocupación por manifestar estructuras, ostentar números y cálculos, e individuar todos los esquemas y las formas sintéticas que puedan 'aferrar' el mundo. Sin embargo, no se puede afirmar rotundamente la indiferencia del autor hacia la materia tratada y las muestras escogidas (pese a que la Metametrica sea un vasto catálogo de textos y curiosidades poéticas ${ }^{14}$ ). No es ninguna casualidad que muchas de las combinaciones presentadas sean de tema religioso: es una obviedad, si pensamos en la situación existencial de Caramuel, pero merece la pena fijarse un poco en algunas de las máquinas acrósticas, los carmina figurata o los de combinación múltiple, para averiguar de qué materiales se sirve el autor, ya que la Metametrica se presenta como un cúmulo bastante desordenado de ejemplos que van amontonándose sin distinción (a veces acompañados solo por breves comentarios, a veces por más extensas explicaciones) ${ }^{15}$.

Sin embargo, si observamos un poco más detenidamente qué tipo de entes metamétricos aparecen en el Primus Calamus, debemos reconocer que -por lo menos en algunas zonas de la obra- se detecta cierta preferencia por parte del obispo de Vigevano.

Consideremos las tablas que ilustran y ennoblecen la primera sección de la Metametrica: son 32 imágenes de varia procedencia (grabadas en veinticinco folios), tan curiosas, elocuentes y representativas del tratado entero, que siempre (o casi) aparecen reproducidas en artículos y estudios sobre la poesía figurada en Caramuel. Estas

13 Giovanni Pozzi, La parola dipinta, op.cit., p. 158.

14 La mayoría de las citas se extraen de composiciones latinas, modernas y antiguas: el carácter de lengua internacional, por un lado, y la presencia de la cantidad silábica ocasionan evidentemente un estudio más rico en combinaciones. Aparecen también, aunque más raramente, poemas y textos en lenguas vulgares (por lo que atañe a la Rhytmica, véase el párrafo siguiente).

15 En efecto, Caramuel trata de de organizar su obra, pero no puede alejar la impresión de que se trata de una tentativa que se le escapa de entre las manos: tener juntos los detalles y el sistema, los elementos concretos y el principio determinador. Lo que llevó a Giovanni Pozzi a expresar, a propósito de la Metametrica, un jucio bastante tajante (que no se ajusta, sin embargo a la Rhytmica, más atentamente trabada): «Il fatto è che non gli importa né di letteratura né di metrica in quanto mezzo di espressività, ma solo di lingue e di versi in quanto ricettacoli di arte combinatoria, ma solo di documenti poetici in quanto esemplificazione di quelle virtualità. Quel vasto campo da noi chiamato enigmistica faceva per lui tutt'uno con la poetica. Per quanto immane, un libro simile non poteva toccare gli sviluppi della poesia e dei poeti veri in Italia [...] fu tuttavia il collettore di una pratica poetica circoscrittta a un ceto per il quale la poesia intesa come arte combinatoria poteva sembrare talora un riscatto dalla sua totale mondanità, tal' altra una saggia ricreazione in mezzo a cure maggiori» (Giovanni Pozzi, La parola dipinta, op.cit., p. 288). 
maravillas icónico-poéticas convierten a las teorías expuestas en el tratado en objetos concretos que hablan a los ojos y a la razón. Pues bien, si miramos más atentamente este manojo de imágenes nos damos cuenta de que la casi totalidad de ellas están pensadas para alabar a hombres de la Iglesia (santos, teólogos, obispos, predicadores etcétera), a Dios, Jesús y María, o a ensalzar dogmas, prácticas y símbolos litúrgicos ${ }^{16}$.

Caramuel parece montar un theatrum mundi, en el que, a través de la picta poesis ${ }^{17}$, pone en escena una malabarística representación del cosmos y la creación. Así que la obra llega a tener fines suasorios: a su manera, es un pequeño jardín de elocuencia, la elocuencia de los laberintos y objetos permutacionales barrocos tardíos, que se hacen espejo y eco de la transcendencia ${ }^{18}$. Un jardín donde hay también muchos frutos y flores más propiamente retóricos, esparcidos en el tejido laberíntico de la obra.

\section{FIGURAE RHETORICAE}

Al exponer la arquitectura de los laberintos poéticos y la naturaleza combinatoria de la poesía, en sus diferentes niveles de estructuración y significación, Caramuel hace abundante uso de figuras retóricas. Para empezar, hay que recordar que los treinta y dos libros que componen la primera parte de la obra toman el curioso nombre de Apollines: tras la epístola dedicatoria y un proœmium, topamos, por ejemplo, con el «Apollo Arithmeticus» (o bien con el «Anagrammaticus», el «Analexicus», el «Anametricus», el «Polyglottus» etcétera). Y los libros van subdividos en capítulos, que toman el nombre de Musae («Peregrina», «Leonina»...), cada una con su numeración y signatura. Y, más allá de la alegoría, cabe también recordar que en el Primus Calamus asoman figuras que

16 Quizás responda al deseo de experimentar con toda libertad y salvedad dentro de lo conocido y bien delimitado (y dogmáticamente eterno e inmutable). Considérese lo que sugiere el análisis de Giuseppe Mazzocchi («Caramuel e la poesia spagnola: leggendo la Rhytmica», Actas del Congreso «L'enciclopedismo e le sue architetture», Vigevano, 14-16 dicembre 2006 -en prensa-) a propósito de la rítimica: «[...] le sezioni previste, con gerarchizzazione ideologica che non serve commentare, sono in ordine di successione le seguenti: 1. Divina; 2. Mariana; 3. Coelestia (su angeli e santi); 4. Heroica (su grandi personaggi); 5. Moralia (è la sezione più ampia, che occupa le cc. XXV-XXXIII); 6. Varia (sezione che raccoglie un po' di tutto, dalla poesia satirica alla piuttosto sacrificata poesia amorosa). [...] la gerarchizzazione dei temi, e anche la scelta che vi è sottesa, tende a rendere moralmente inattaccabile tutta l'operazione; ma nel momento in cui la classificazione tematica non ha più ricaduta alcuna sullo sviluppo del libro e la sua organizzazione, la lezione, sottile ma energica, non sovvertitrice ma ben delimitante i campi di pertinenza, è appunto quella dell'autonomia della parola poetica».

17 La picta poesis se acerca así -sin coincidir, evidentemente- a la función de los jeroglíficos que el siglo XVII ha elevado a menudo a forma communicandi, por ejemplo, en los sermones (cf. Giuseppina Ledda, Los jeroglíficos en los sermones barrocos, en La parola e l'immagine, ETS, Pisa, 2003, pp. 111-128).

18 La obra entera -subraya Martone- se hace laberinto: «Non esiste, nella Metametrica, alcun indice della stessa [...] un testo nel quale non sono previste vie di attraversamento, e dove la immagine del labirinto, aspira, essa sì invece, a porsi quale privilegiata figura testuale, anzi come la testualità medesima di cui si fa qui questione» (Arturo Martone, op. cit, p. 251, en la nota). Es una obra que pasó por manos de varios tipógrafos, y en la que la paginación vuelve a empezar muchas veces, ocasionada -por ejemplo- por la aparición de un nuevo Apollo. 
podrían encontrarse en cualquier 'abecedario' de poética o de elocuencia: en el primer tratado, se ponen ejemplos de rapportatio, de anaphora o de uso del adjetivo con función ornamental $^{19}$. Por otro lado, se advierte cierta atención hacia lo retórico, gracias a las muchas referencias, repartidas a lo largo de la enciclopedia, a la predicación y los predicadores (con su 'herramienta' profesional); y también gracias a las enseñanzas y modelos retóricos se pueden extraer de las homilías o emplear en paralelo a la retórica eclesiástica. La retórica aparece como telón de fondo -presente pero que se nota solo de vez en cuando- detrás del discurso principal, sea metamétrico sea rítmico.

Lo que voy a presentar aquí es un primer intento de análisis, para rastrear indicios y huellas de esta presencia.

\section{Una METAMETRICA 'RetóRicA'}

1) En uno de los paratextos introductorios (el Proæmium), el cisterciense exhibe sus argumento ${ }^{20}$ para defender el ars metametrica, mostrar su autonomía científica y convencer de que no se trata de una imitación católica de la cábala judía ${ }^{21}$. En los articuli del Prodromus Metametricus (o Tractatus Proemialis, que curiosamente precede al Proœmium), pone un ejemplo de panegírico, en que la homilética es elemento temático fundamental: el discurso sobre la elocuencia de un afamado concionator es, a la vez, buena ocasión para entrenarse en el uso de la gramática latina ${ }^{22}$. Un breve elogio de San Francisco de Sales ${ }^{23}$ se convierte inmediatamente en ejercicio de análisis gramatical y estudio retórico-estilístico: en las glosas marginales, a la hora de presentar las virtudes concionatorias de san Francisco, un predicador que se opuso eficazmente a la herejía calvinista, Caramuel comenta el uso de verba y nomina, en sus posibles empleos lingüístico-combinatorios. Gramática y estilística se ponen al servicio de la predicación y de la ortodoxia. Aparecen aquí los recursos típicos de la homilética, como el exemplum, la dispositio bien trabada, la variatio en la permanencia semántica (o

\footnotetext{
19 Juan Caramuel y Lobkowitz, Metametrica, op. cit., Apollo Glottographus, Musa I, Anaphorica, p. 24; Apollo Sylvanus, Musa III, Adiectiva, p. 124; Apollo Fulminans, Musa I Aurea Descendens, pp. 47-58.

20 Ibidem, Articuli IV-VII, pp. 8-16.

21 Ibidem, pp. 10-16.

22 El texto está colocado inmediatamente después de unas páginas reservadas a una rápida reseña de las normas de la lengua de Cicerón. El Prodromus Metametricus (op. cit., pp. I-XXXII) reúne, en efecto, una gramática comparativa enfrentada -con reglas y normas del buen uso- de las lenguas italiana y española, y un linguae latinae breviarium.

23 «Ad laudem B. Francisci Salesii panegyris. Ut praecedentes regulas melius Philomusus percalleat, frequentem orationem in paragraphos divisimus, illosque ut periodus responderet periodo, numeris arabicis distinximus, notavimusque, sicut \& sintaxim ipsam distinxeramus \& notaveramus» (Juan Caramuel y Lobkowitz, Metametrica, op cit., Prodromus, pp. XXXIII- XXXVIII). Las glosas al margen llevan título gramatical: De nominum appositione; De genitivo possessionis, Genitivus abundantiae $\mathcal{E}$ inopiae; Similis $\mathcal{E}$ dissimilis; Dativus post nomen; Opus indeclinabile; Dativus post verbum; Verba activa etcétera.
} 
juego sinonímico) y la elencatio. Ha aquí algunos pasajes del texto y del comentario de Caramuel:

\section{Prodromus Metametricus}

[1] Beatum Franciscum Salesium, Galliae Phoenicem, Europae Decus, ornamentum Scholę, pontificię perfectionis ideam, generis humani prodigium: cuius jam anno

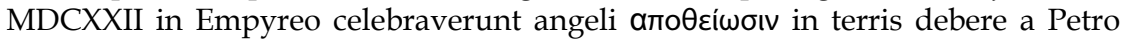
nunc sedente [....] coelitum albo inscribi, stupenda prodigia, prodiosa miracula, miraculosae suadent gratiae, quibus decoratur divinitus, \& ob quas a toto orbe christiano celebratur humanitus ${ }^{24}$ (p. XXXIII).

[2] Fuit, etiam dum esset adolescens, recti tenax, nullius culpae conscius, virtutibus avidus, \& scientiarum sublimium studiosus; semper beneficij, vel levissimi memor, injuriae, vel gravissimae immemor, rumorum, \& murmurationum securus [...] (p. XXXIII).

[7] Tandem, ut sibi bene consuleret, \& deo tutius serviret, clericali militiae adscribi voluit, \& antiquae pietati, \& puritati incumbens, \& consonans, evangelicis illustrium concionatorum orationibus frequenter interfuit, vitaeque exemplo sibi subditis, \& praefuit \& profuit: nemini offuit aut nocuit, sed omnibus favens \& auxilians, singulis charissimus fuit ${ }^{25}$ (p. XXXV).

[10] Tanta contra calvinistas concionabatur efficacia, ut Auviliacum perillustrem dynastam, haereticum pertinacissimum \& in controversiis apprime versatum ita perstrinxerit, ut abjurata haeresi religionem catholicam amplexus sit. Hinc ab orthodoxis suspici, timerique ab Heterodoxis, incepit ${ }^{26}$ (p. XXXVI).

[12] Accusabat (arguebat, postulabat, damnabat) blasphemiarum horribilium Ioannem Calvinum, a republica olim lilii gallici inustione punitum: \& licet non absolutum crimine, supplicio ultimo per imprudentiam liberatum. Catholicae doctrinę veritatem tam efficaciter singulis persuadebat, ut hęresiarcha inciperet parvi (minoris, minimi) fieri (haberi, ęstimari) flocci duci seductor, \& qui pendere debuisset, nauci pendi ${ }^{27}$ (p. XXXVI).

NOTA [colocada al final del apartado]

Sic volui de B. Francisco Salesio, ut Philomusos docerem syntaxim, \& adversus virum sanctissimum augerem devotionem, scribere: cuicumque magistro erit liberum hanc orationem imitari \& sibi aliud qualecumque argumentum proponere, imo uberius si voluerit discurrere: mihi enim placuit esse brevi (p. XXXVIII).

${ }_{24}$ Glosa: Plura substantiva, aut substativum, E adjectivum si componantur, aut apponantur verius, concordant

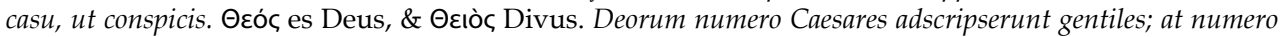
divorum ecclesia illos, qui vixerunt sanctissime, E clarent post mortem miraculis. Ideo Apotheosim non per $\varepsilon$, sed per eı scribi debere a nobis iudicamus [sub dio, in loco aperto, $\mathcal{E}$ libero].

25 Glosa: Datious post verbum .7. Incumbo (obnixe alicui rei operam do) aut dativum; aut accusativum cum in aut ad Cicero De Orat. In id studium, in quo estis, incumbite. Et Libro 10. Epist. 10. Incumbo toto pectore ad laudem.

26 Glosa: Verba activa: sunt multa \& notissima propter accusativum, quem regunt; et ut vel pueri sciunt, haec positio, Timet Calvinista Salesium, transit in passivam hoc modo, A Calvinista Salesius timetur.

27 Glosa: Genitivus criminis cum verbis accusandi transire in ablativum potest cum praepositione de, unde ubi dixi: Accusabat blasphemiarum Calvinum, potui dicere de blasphemiis. Sed unde ille genitivus nascebatur? A voce de crimine subintellecta: est enim idem, Appello Iohannem proditionis, ac Appello Iohannem de crimine proditionis. 
2) En el Proœmium se ofrece una definición de los laberintos, que explica la relación analógica entre retórica, poesía, música y metamétrica, ciencias capaces de producir implicatas et inextricabiles orationes, es decir, laberintos. Es el pasaje en el que se aclara la elección de los términos Apollines y Musae:

Architectos sunt imitati rhetores, \& orationem vehementer implicatam, et inextricabilem labyrinthon appellant. Sequuti sunt poetae, \& musici, qui numeris metricis, \& sonoris multos formarunt labyrinthos. Artem hanc, quam veteres musae non docent, quam nescit antiquus Parnassus, ultra Parnassum, \& scientiam metricam reperi, \& ideo metametricam vocari volui; et quia est ditissima, \& copiosissima, per ulteriora tempe distributam apollinibus diversis consecravi. Unum tantum venerati sunt veteres; at nos in ulterioribus Elisijs, triginta, vel plures invenimus, omnes conceptuum divites, omnes ingeniosos, \& doctos. Singuli fontes suos, singuli musas \& genios habent. Iuxta varietatem materiae distinguuntur, multiplicanturque: \& mille modis currunt, recurrunt; labuntur, volitant, circumgyrantur. De singulis scribemus inferius: modo artem totam ad brevem synopsim reducamus; \& apollines enumeremus, ut lector sciat, quales debeat a singulis influxus, \& ideas impetrare ${ }^{28}$.

3) Según nos recuerda Mercedes Blanco, en la teoría retórica de Ormaza, «idealmente, si no siempre en la práctica, cada unidad léxica será escogida no tanto por su significado estable, codificado por sus empleos, como en virtud de atracciones y repulsiones fónicas y semánticas que la relacionen con otras unidades, de modo que el sonido sea eco del sentido» ${ }^{29}$. La conexión entre formas diferentes, fundada en principios de afinidad semántico-sonora, se presenta -obviamente- también en la Metametrica. Por ejemplo en el Apollo Anagrammaticus: el verdadero anagrama, inteligente y agudo, sabe juntar la reformulación de la superficie gráfico-sonora y la dimensión del significado. Si «Ludovico Ariosto» es un «Altro Ovidio Tosco», la fórmula «Pater Aeternus, Verbum, \& Spiritus Sanctus» puede interpretarse también como «Semper beatus; ac, ut unus, est pariter trinus»; «Sancta Teresia» se convierte en «Ista sane recta»y «Beatus Ignatius Loiola» ha da leerse, con un pequeño retoque (o > e), como «Ego sane vita illibatus» ${ }^{30}$. De la misma manera, el capítulo Apollo Paromœus recupera -entre otras cosas- la técnica poética de los Centum Disticha de Leporeo (Roma, 1653), gracias a la que el parentesco fónico-gráfico, en los carmina abecedaria, se asocia a la función definitoria. Un ejemplo puede ser suficiente:

Academicus Aristotelicus

Alter Apollo avidos animos alis almus adactor;

Alter Aristoleles agis, afficis, arguis actor ${ }^{31}$.

\footnotetext{
${ }^{28}$ Juan Caramuel y Lobkowitz, Metametrica, op. cit., Proœmium, Articulus II, De labyrinthis, pp. 4-5.

${ }^{29}$ Vid. Mercedes Blanco, «Humanismo rezagado frente a difícil modernidad. Al margen de la polémica Ormaza-Cespédes sobre la oratoria sagrada», Criticón, 84-85 (2002), pp. 123-144 (137).

${ }^{30}$ Juan Caramuel y Lobkowitz, Metametrica, op. cit., Apollo Anagrammaticus, Musa IV, Genuina (inspirada en las Metamorphoses nominum, de Jerónimo Genuino, Roma, 1640), pp. $42-56$ (42, 43, 55).

${ }^{31}$ Ibidem, Apollo Paromœus, pp. 198-214 (202).
} 
4) En el ejemplar consultado (Biblioteca Universitaria, Pavía, sign. 160. N. 1.), en la sección conclusiva del primer volumen de la Metametrica (a continuación del Apollo Fulminans), encontramos las célebres láminas antes mencionadas. Según se comentaba, el tema religioso abunda entre dogmas y figuras de la historia sacra. La poesía se combina aquí con emblemas o elementos figurativos que comunican de inmediato el mensaje, porque verbum et imago se completan recíprocamente. Si en los sermones se emplean jeroglíficos, pinturas, dibujos y objetos que estimulan la visión (más contundentemente de lo que pueden las palabras, según recuerdan muchos predicadores), Caramuel elige una serie de tablas para su personal oratoria, dirigida a ese público selecto que puede comprender la síntesis de visual y lingüístico, y su significado ${ }^{32}$.

Los varios laberintos circulares remedan, por ejemplo, tópicos de la predicación, como la amplificatio sobre temas (se trate de citas bíblicas u otras). En el caso de las tablas XXIV y XXVbis, las equivalencias Jesus = Sol y Maria = Maris stella funcionan como punto de arranque: los nombres de Cristo y de la Virgen están colocados en el centro de una serie de círculos concéntricos, cada uno de los cuales enumera y predica posibles qualitates y proprietates de los dos. El poeta sagaz podrá seguir su camino centrífugo, ensartando variamente atributos y fórmulas que describan al Salvador y a su Madre. Se pueden montar y desmontar, de esta manera, poemas permutacionales que ofrecen una curiosa mezcla de astronomía y poesía, donde las órbitas y los movimientos rotatorios permiten la producción de un sinfín de composiciones en paralelo $^{33}$. La dispositio de los cielos, participa de las variaciones y de las permutaciones metamétricas (y retóricas) de la palabra poética.

\footnotetext{
32 Tal combinatoria es el resultado concreto de dos conceptos esenciales en Caramuel: la libertad y la razón. Se ha dicho que «l'homme de Caramuel est le plus proche parent de l'ange, doté d'une intense liberté devant la loi positive. Mais cette liberté va de pair avec une grande faiblesse, qui implique la necessité d'un auxiliaire: la raison» (Jean-Robert Armogathe, «Probabilisme et libre-arbitre: la théologie morale de Caramuel y Lobkowitz», en Paolo Pissavino (ed.), Le meraviglie del probabile. Juan Caramuel (1606-1682). Atti del convegno internazionale di studi, Vigevano 29-31 ottobre 1982, Vigevano, Comune di Vigevano, 1990, pp. 35-40, 37). Efectivamente, en estas máquinas y esquemas, que son productos de la racionalidad, de los análisis y síntesis racionales, se manifiesta plenamente la libertad del ser humano, que puede juntar variamente, teóricamente hasta el infinito, los elementos lingüísticos y poéticos de los que dispone: para predicar, por ejemplo (según lo hacen los oradores sagrados) los atributos de la Virgen, de Cristo, y en general de Dios, quien nos concedió rationem, libertatem y rem combinatoriam.

33 Juan Caramuel y Lobkowitz, Metametrica, op. cit., Apollo Multiformis, Crux Coelestis, pp. 66-74 (p. 68): «Erat similis coelo Liliueldensi delineatio: duplex tamen; nam altera Christo Soli, et altera Mariae Cynosurae (maris stellae) dedicabat. Unde non solum singula systemata seorsim sumpta in numerum versuum maximum adscendebant: sed alterum in alterum se insinuans, excrescebat in multitudinem fere infinitam».
} 


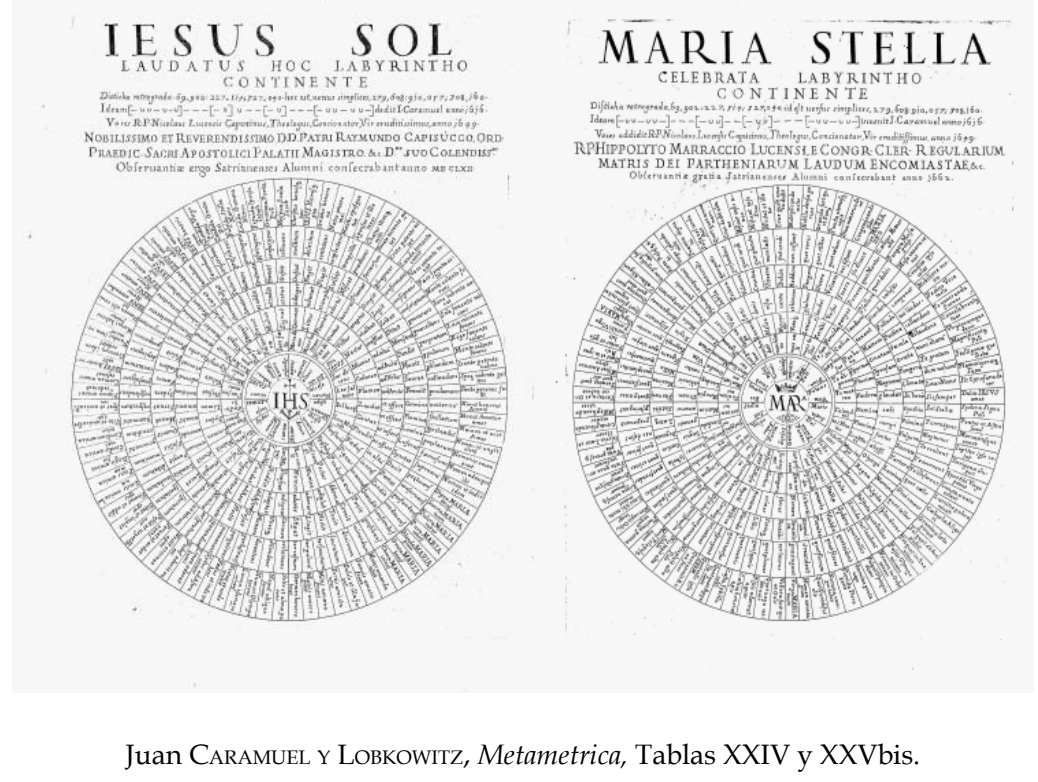

La tradición, ya antigua, de los carmina figurata es elemento fundamental para explicar la estructura y el funcionamiento de estos objetos metamétricos, pero no podemos olvidar que algunas de estas obras salieron propiamente de la pluma de concionatores, como es el caso de los poemas permutacionales de Nicolás de Lucca, o que iban dirigidas a predicadores.

Es más: la fórmula combinatoria del concionator Nicolás de Lucca que produce la tabla XXVbis (Maris Stella $=$ Maria), a partir de una intuición del mismo Caramuel («Ideam [...] inuenit Caramuel anno 1616, voces addidit [...] Nicolaus Lucensis [...] anno 1649») antes recordada, aparece explicada en el texto de la Metametrica, inmediatamente después de un pasaje sacado de una homilía de Bernardo de Claraval (Super missus est Gabriel), que sirve como introducción al tema, ya que explica por qué el título de Maris Stella resulta perfectamente adecuado a la santísima Virgen. Una serie de enlaces metafóricos semejantes a los que alimentan el artilugio barroco reproducido por Caramuel:

Universis praecelsa Iesus \& Mariae nomina pie colentibus ad spectandum \& obervandum delineata, proposita, atque oblata ab omnium infimo tantae reginae cliente Nicolao Lucensi Fr. Min. Capucino Concionatore. Anno MarIae LVCIDo ${ }^{34}$ :

\footnotetext{
34 Ibidem, p. 69. Recuerda aquí Caramuel la Cynosura sive Mariana Stella Polaris del capuchín Niccolò Barsotti de Lucca o Nicolaus Lucensis (Viennae, typis Joannis Jacobi Kürner, 1655 y 1657 -nótese que el año de publicación aparece anagramado dentro de la expresión Anno MarIae LVCIDo = MDCLVII-), cuyas dotes alaba (subrayo el uso del verbo exornare): «Sublimiores scientias Charitibus Castaliis exornat: et quia veteres nostras ideas novis verbis exornare dignatus est, volui suo labore et ingenio
} 


\section{Bernardus Homil .2. super Missus est [In Luc. I, 26, 27]}

Loquamur pauca \& super hoc nomine (MARIA) quod interpretatum maris stella dicitur, \& Matri Virgini valde convenienter aptatur. Ipsa namque optime syderi comparatur: quia sicut sine sui corruptione sydus suum emittit radium, sic absque sui laesione Virgo parturit filium. Nec syderi radius suam minuit claritatem, nec Virgini filium suam integritatem. Ipsa est igitur nobilis illa stella ex Iacob orta Num 24. cuius radius universum orbem illuminat, cuius splendor \& praefulget in supernis, \& inferos penetrat, terras etiam perlustrans, \& calefaciens magis mentes quam corpora, fovet virtutes, excoquit vitia. Ipsa, inquam, est praeclara et eximia stella super hoc mare magnum \& spaciosum necessario sublevata, micans meritis, illustrans exemplis. O quisquis te intelligis in huius saeculi profluvio magis inter procellas \& tempestates fluctuare, quam per terram ambulare, ne avertas oculos a fulgore huius sideris, si non vis obrui procellis. Si insurgant venti tentationum, si incurras scopulos tribulationum, respice stellam, voca Mariam. Si iactaris superbiae undis, si ambitionis, si detractionis, si aemulationis, respice stellam, voca Mariam. Si iracundia, aut avaritia, aut carnis illecebra naviculam concusserit mentis, respice ad Mariam. Si criminum immanitate turbatus, conscientiae foeditate confusus, iudicii horrore perterritus, barathro incipias absorberi tristitiae, desperationis abysso, cogita Mariam. In periculis, in angustiis, in rebus dubiis, Mariam cogita, Mariam invoca. Non recedat ab ore, non recedat a corde, \& ut impetres eius orationis suffragium, non deseras conversationis exemplum. Ipsam sequens non devias: ipsam rogans non desperas; ipsam cogitans non erras. Ipsa tenente non corruis; ipsa protegente non metuis; ipsa duce non fatigaris; ipsa propitia pervenis. Haec ille ${ }^{35}$.

El estilo, con su amplificación, su acumulación progresiva, sus paralelismos sintácticos y sus anáforas es ejemplar: en la homilía estos sintagmas están desplegados en su dimensión horizontal, pero podrían considerarse como paradigmáticamente alternativos o sintagmáticamente presentes a la vez, así como, in nuce, ya en la tabula ofrecida en estas páginas por Caramuel, como anticipación de la laberíntica picta poesis colocada al final del tomo ${ }^{36}$ :

Ut nova conformare possis coelorum metametricorum systemata, materiam subministrat idem author (R. P. Nicolaus Lucensis) frequentem exhibendo tabulam [...]

\begin{tabular}{|c|c|c|c|c|c|c|}
\hline $\begin{array}{l}\text { Sponsa Maria } \\
\text { Dei }\end{array}$ & $\begin{array}{l}\text { Te } \\
\text { laudent }\end{array}$ & Flamina & Caeli & Lumina & Sol, stellae & $\begin{array}{l}\text { Sydera, } \\
\text { Pontus, Aquae }\end{array}$ \\
\hline $\begin{array}{l}\text { Natio } \\
\text { quaeque soli }\end{array}$ & $\begin{array}{l}\text { Te } \\
\text { exaltent }\end{array}$ & Flumina & Campi & Te juga & $\begin{array}{l}\text { Luna, } \\
\text { ignes }\end{array}$ & $\begin{array}{l}\text { Tellus, \& } \\
\text { astra colant }\end{array}$ \\
\hline $\begin{array}{l}\text { Quot tibi } \\
\text { Virgo parent }\end{array}$ & Tot reges & Fulmina & Fontes & Te mare & Neptunus & $\begin{array}{l}\text { Iupiter ipse } \\
\text { colat }\end{array}$ \\
\hline $\begin{array}{l}\text { Cuncta creata } \\
\text { colant }\end{array}$ & $\begin{array}{l}\text { Tot } \\
\text { gentes }\end{array}$ & Daemona & Abyssi & Stemmata & $\begin{array}{l}\text { Tot } \\
\text { mentes }\end{array}$ & $\begin{array}{l}\text { Terrigenae, } \\
\text { superi }\end{array}$ \\
\hline
\end{tabular}

coelestem hanc musam honorare. Scripsit, ut superius adnotasse me memini, Marianam Cynosuram, in qua quam sit ingeniosus poeta, et quam subtilis mathematicus tota schola videt, suspicit, et applaudit. Hunc numerosum ille Labyrinthum edidit Viennae anno 1655 auctioremque recudi curauit ibidem anno 1657. Eamdem ut curiosus lector, suspiciat admireturque huc adponi curaui» (p. 67).

35 Ibidem, p. 69, cols. 1-2.

36 Ibidem, p. 70. 
En la tabla XIX, De augustissimo Eucharistiae sacramento, se representa una imagen donde conviven, a diferentes niveles: 1) la poesía latina con sus hexámetros, que exaltan el pan angelicus (en horizontal); 2) la lectura cruzada (diagonal y vertical), recombinada, de algunos elementos grafemáticos de los versos, que produce los sintagmas: OSALUTARIS HOSTIA; ECCE PANIS ANGELORUM; EGO LUX MUNDI; VIDE ET GUSTA; EDITE ET BIBITE EX HOC OMNES; 3) el dibujo de la hostia y la copa de vino (y de las cintas que adornan la escena), en que están insertadas estas breves oraciones. Por lo cual, la co-presencia de versos y citas evangélicas se refuerza gracias al material icónico que los reúne y ofrece la recta interpretación ${ }^{37}$.

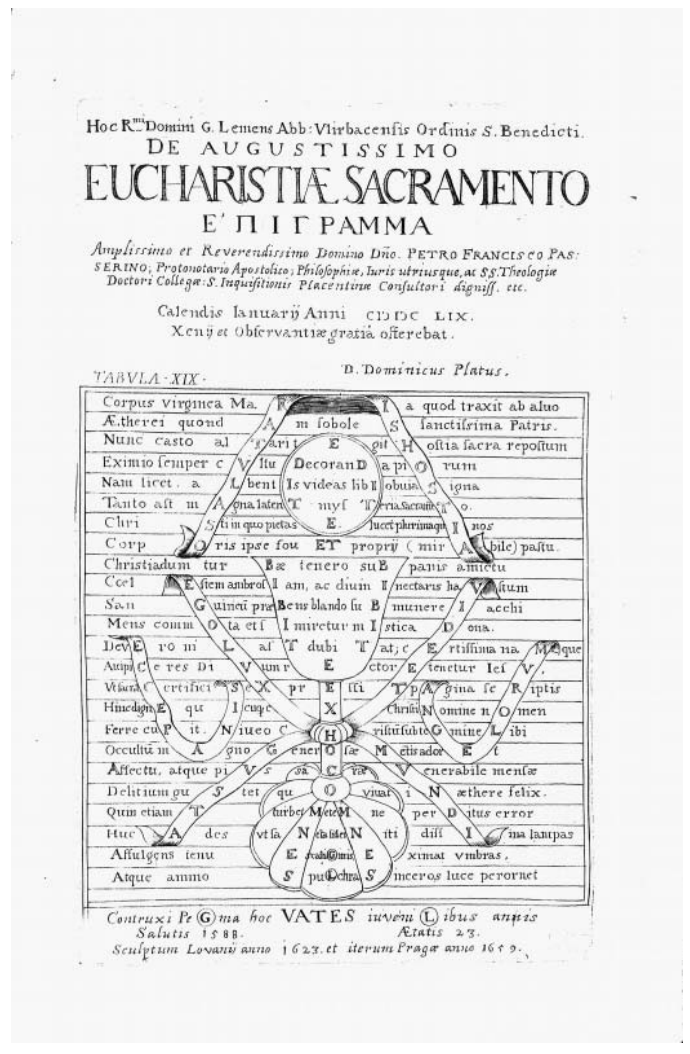

Juan CARAmuel y LobKowitz, Metametrica, Tabla XIX.

37 Todo ello nos remite a una observación de Caramuel que Giovanni Pozzi ya resaltaba (La parola dipinta, op. cit., p. 255): «Praeterea potentia oboedientialis, ut vocant, concedit ut jubente Deo, ex omni creatura fiat quaelibet; et omnis creatura faciat quamlibet; ut videntur in Romanae Ecclesiae Sacramentis; nam panis convertitur in Corpus, \& Vinum in Sanguinem Domini Nostri lesu Christi; \& verba, tametsi sunt corporea, supernaturalem gratiam, characterem, \& alias incorporeas qualitates producunt. Quaerenti mihi exemplum, ut tres istas res dilucidarem, anagramma succurrit. Virtus enim anagrammatica, ex qualibet re facit quamlibet, ex prosa enim carmen, \& uno senso, aut sententia format aliam toto coelo diversam» (Juan Caramuel y Lobkowitz, Rhytmica, Campaniae, ex officina episcopali, 1669, Epistola IX, p. 651). 
Finalmente, en este (ya clásico) apartado caramueliano sobresale una tabla sino-latina (la número XXIV), que podemos colocar al margen de la interesantísima literatura jesuítica sobre Oriente, que testimonia los esfuerzos para apoderarse del idioma chino y predicar en él los principios de la fe cristiana. Se enfrentan, según la mecánica de siempre, una tabla cuadrangular, cuyos campos están ocupados por los atributos útiles para presentar eficazmente en idioma chino a la Societas Jesu (también gracias a las 'coordinadas sagradas' de Jesús, María y San Ignacio, que la rodean) ${ }^{38}$; se adjuntan una tabla con la transliteración de la lengua oriental, y una con la traducción al latín.

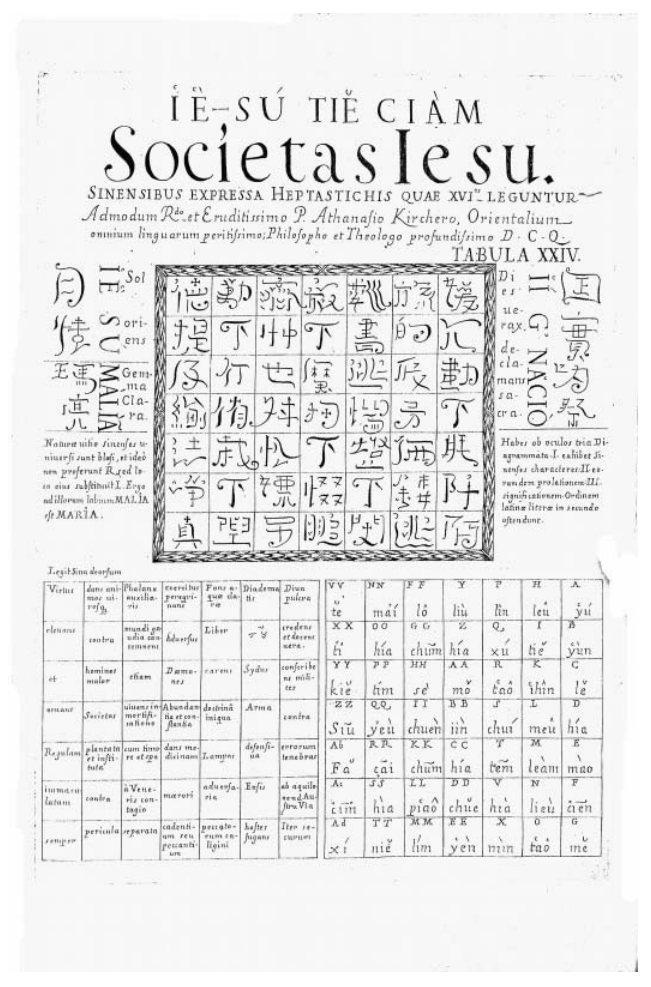

Juan Caramuel y LobKowitz, Metametrica, Tabla XXIV.

\section{RHYTMICA Y RETÓRICA}

En la segunda parte del tratado, el más importante manual de métrica y rítmica de la época ${ }^{39}$, el recopilador va paseando sobre todo por los bosques de la poesía

38 Donde la grafía MALIA, según explica la misma tabla (véase la imagen), reproduce la pronunciación china del nombre latino.

39 Cf. Emiliano Díez Echarri, Teorías métricas del siglo de Oro, Madrid, CSIC, 1970. 
española, si bien no faltan ejemplos en otros idiomas, modernos y antiguos. Si las novedades de la poesía italiana escasean, es verdad que Caramuel conoce muy bien la poesía de su patria y está al tanto de las últimas tendencias. No se trata de fríos listados de nombres y versos, sino de una rica y muy provechosa antología. Los versificadores preferidos son Góngora (que domina tanto aquí como en el primer volumen), Francisco de Borja príncipe de Esquilache, Quevedo, Garcilaso, Calderón y Lope, López de Úbeda, Jerónimo de Cáncer, Garcilaso, Anastasio Pantaleón de Ribera ${ }^{40}$. Pero también -y esto no es para nada sorprendente- el fray trinitario Hortensio Félix Paravicino, predicador real de Felipe III y Felipe IV, autor de sermonarios y epitafios, amigo de Góngora y Lope de Vega, y poeta. Sus obras poéticas ${ }^{41}$ se ven literalmente saqueadas por Caramuel ${ }^{42}$ : de Paravicino se proponen algunos romances profanos, pero sobre todo numerosos romances de corte religioso y hasta teológico (según un uso bastante frecuente: piénsese en el solo modelo de José de Valdivielso).

Son composiciones en las que el poeta escribe versos casi como si fueran sermones, ocupándose de temas como la adoración de la cruz y la visión, llena de estupor, del crucificado, las invocaciones al Salvador, la ascensión de la Virgen, el sacramento de la Eucaristía ${ }^{43}$.

En los intersticios en prosa entre un poema y otro Caramuel coloca una serie de comentarios donde se explica el sentido de la littera y la sentencia, añadiendo referencias al mundo (personas o costumbres actuales, que conectan con el tema tratado). Todo ello sirve para formar un tejido de relaciones históricas, lógicas y, sobre

\footnotetext{
40 Sobre esto, véase el estudio de Giuseppe Mazzocchi, op. cit.

${ }^{41}$ Cf. Francis Cerdan, «Bibliografía de Fray Hortensio Paravicino», Criticón, 8 (1979), pp. 1-149.

42 En la Rhytmica (op. cit., p. 328) se recuerda que «Eruditissimus poeta, \& eloquentissimus orator, P. Hortensius Foelix Paravisinus, hoc numero, ut constat ex praecedentibus, specialiter delectabatur, \& praeter alias ideas [los esquemas métricos], quas iam dedimus, hanc invenit».
}

${ }_{43}$ Se trata de: un romance de heptasílabos Hermosísimo lucero (Ibidem, p. 124), en el que se expresan las innumerables prerrogativas de la Madre de Dios, según la técnica de la enumeratio; otro romance (de tetrásticos asonantes) sobre el sacramento de la Eucaristía y el portento de la transustanciación (Mal podéis disimularos, p. 126); la traducción del himno Lauda Sion Salvatorem, que (en palabras de Caramuel) sería digno de ser cantado en la fiesta del Corpus Christi, igual que el original de Santo Tomás (Alma, en himnos, y cantares, pp. 127-128); un romance que pinta a Cristo colgando de la cruz (De aquella montaña al ceño, pp. 128-130: «Sunt sequentiae tetrastichae, quae te simul possint pietatem \& eruditionem docere», en virtud de su fuerza suasoria); otros dos romances de meditación sobre la gloria de la Cruz y su recuperación (Al espectáculo grande, pp. 130-131; Oh nuevamente glorioso, pp. 132-133) «hanc celeberrimam historiam Hortensius ad maiorem inventae Crucis gloriam his assonantis illustravit»; finalmente, un retrato de la Pasión (Pendiente a morir de un leño/ teatro estupendo, y triste, pp. 134-135).

Una tensión análoga a la de Paravicino se percibe en dos composiciones del príncipe de Esquilache, dos canciones-meditaciones sobre un cráneo (típico símbolo de la muerte, a menudo exhibido en las iglesias durante la misa), y sobre la Cruz, que transmiten la sensibilidad del sermón barroco frente a temas emotivamente tan fuertes como éstos. Se trata de A una Calavera («carmina sunt devota, \& spiritus Divini plena, \& ideo illa subjungo») y Oh ya gloriosa infamia («Sed \& reperio ad laudem Sanctissimae Crucis unum canticum inter poëmata sacra [...] Piae eruditionis gratia Elogium de Cruce propono»), Ibidem., pp. 299 y 299-300. 
todo, discursivas, que permite mantener unidos los diferentes ejemplos, más allá de la coincidencia métrica (todos son romances). Es aquí donde el cisterciense resalta la actividad de inventor de estrofas y esquemas métricos de Paravicino ${ }^{44}$, pero la estrecha conexión entre las dos personalidades del trinitario, la concionatoria y la lírica, se ve en el tercer libro: al comentar una silva de consonancias de formas verbales, Caramuel introduce una reflexión sobre el uso de la segunda persona del plural, que consiente cierta variedad morfológica y poética (amábais, amábades, etcétera). La glosa aclara un mecanismo de interrelación entre poesía y predicación ${ }^{45}$ :

Pater Hortensius Foelix Paravicinus in sermone de Mandato fol. 154. col $3 \mathrm{sub}$ finem. Os pareció a vos, que lo padecisteis, que era nada. Ecce utramque opinionem conjungit. Consonat sibi in poëmate (Romance) ad Crucifixum, quod pagin. 134 legisti. Ibi inter alia cecinit: En alto clamor la quexa / sobre los cielos pusisteis $\mathcal{E}$ c. / No pretendo, no acordaros, / lo occupado, que enstuvisteis Ec. / Desta escritura gallarda / los primores, que la disteis $\mathcal{E} c$. [... $]^{46}$.

El contacto entre oratoria y poesía aflora también en otras ocasiones. Al comentar el poema del trinitario Murió el César Filipo, rasgó el templo, se plantea el problema del uso del apelativo Caesar, a propósito del rey Felipe II. Caramuel opone -a eventuales críticos- varios argumentos de tipo retórico sobre la congruidad entre estilo y género, basándose en el comportamiento de un modelo latino: la obra del escritor francés (arzobispo de la ciudad de Rouen, y luego de París) François de Harlay, que -él también- tildaba de Caesar al rey de Inglaterra:

Si obicias Harlaeum loqui poëtice, respondebo, instantiam tuam nec esse veram, nec ad rem. Non ad rem: quia Hortensius Philippum, non in concione evangelica, sed in poëmate panegyrico Caesarem nominarat. Non veram, quia saepe etiam Harlaeus eumdem Angliae Regem Caesarem nominat; nempe quando non numeris metricis indulget, sed soluta oratione res gravissima tractat Lib. I. cap. 26 Haec pro te, Iacobe, tanquam pro Britannico Caesare, Ecclesiae vota sint, ut habeas unde nihil praeter coelum Constantino invideas $[\ldots]^{47}$.

Hay más predicadores en la Rhytmica. Predicador es también el autor de uno de los poemas in mortem Lupi de Vega: el soneto Agora sí que hay Fenix, que hasta agora, que se debe a la labor poética del padre Hernando de Camargo y Salgado ${ }^{48}$. Aun en la parte final de la Rhytmica, donde Caramuel inserta una colección de breves tratados en

$44 \quad$ Ibidem, p. 232.

45 Ibidem, (liber III, sobre las silvas), p. 480.

46 Se cita aquí el romance, Pendiente de un leño, antes recordado en la nota 43.

47 Juan Caramuel y Lobkowitz, Rhytmica, op. cit., p. 328.

48 El soneto forma parte de la Fama póstuma, de donde [fol. 53b] lo saca Caramuel, junto a muchos otros poemas de varios autores: «Obiit Lupus de Vega, quem nominasse, laudasse sit, \& Hispani poëtae eius famam posthumam (liber est impressus Matriti anno 1636) poëmatibus variis exornarunt, \& inter alios p. Ferdinandus Camargo \& Salgado Augustianianos numeros eloquentes profudit» (Ibidem, pp. 385-386 [i.e. 395-396]). 
forma de Epistolae, se menciona a varios poetas-predicadores. En la primera epístola, una reseña crítica de la célebre obra Del modo di comporre in versi nella lingua italiana (o Rimario), de Geronimo Ruscelli (Venezia, Giovanni Battista e Melchiorre Sessa, $1559)^{49}$, se examina el fenómeno del encabalgamiento ${ }^{50}$. Tras haber mencionado los ejemplos que el tratado renacentista italiano le facilitaba, decide ampliar el abanico de muestras poéticas, añadiendo también algunas piezas ibéricas. No parece ninguna casualidad que escoja una serie de sonetos-epitafios, compuestos en la muerte de un regius concionator, el padre Nicolás Bautista, difunto en el año 1663. Dos de ellos insisten en lo más propio de la profesión del predicador, en una elocuencia unida a la santidad, celebradas gracias a una curiosa y ejemplar dispositio retórica de la sintaxis en el soneto ${ }^{51}$.

Pero la expresión más perfecta de la visión de Caramuel se revela, quizás, cuando el cisterciense introduce la cita de otro soneto, salido de la pluma de Jerónimo Cáncer de Velasco, y titulado Esa mustia beldad que enamorado. La composición retoma el antiguo tema de la caducidad y fragilidad de la belleza, cargado, en este caso, del sentimiento barroco del desengaño. Ahora bien, para introducir el poemita, el obispo de Vigevano echa un breve discursillo, que suena así:

${ }^{49}$ Ibidem, pp. 513-521: «[...] examinat Hieronymi Ruscelli librum agitque de versibus et rhytmariis italicis. Quanta Eloquentia fieri debeat ostendi: probatque viros alias doctos carere interdum gloria eloquentiae defectu». Es también digna de mención la número XXI, «De arte condendi comoedias disserit; \& ejus leges, \& regulas non violasse sed correxisse Lupum de Vega evidenter ostendit; doctrinamque omnibus poetis necessariam dilucidat» (Ibidem, pp. 690-718) sobre el arte de hacer comedias. Al lado de la defensa del héroe del teatro nacional barroco (Lope), se ofrecen (pp. 704-707) varias indicaciones sobre la dispositio, la eloquentia la memoria, la pronuntiatio y la affectuum expressio, que remiten declaradamente a la visión retóricamente decorosa del género y la obra.

50 Ibidem, p. 518: «Capite XII. Disputat de sonetto Ruscellus \& movet curiosam quaestionem, cujus dissolutio omni carminum generi adaptari debebit. Quaerit igitur, an sensus debeat cum singulis versibus terminari, an potius versus interrumpere \& ex medio in medium procedere?».

51 Ibidem, pp. 518-519: «Matriti 14. Augusti 1663. desiit esse mortalis reverendissimus p. mag. Nicolaus Baptista, Ordinis Carmelitani gloria, regius concionator, aut etiam rex concionatorum; vir vere apostolicus, apud doctos \& nobiles magnum sui desiderium relinquens». Un colega suyo, el padre Miguel de Cárdenas, se puso, entonces, a escribir el soneto que sigue: «Ya murió la verdad* [el asterisco marca la fin de cada unidad sintáctico-semántica, en oposición a la estructura del verso] en quien vivía/ la santidad unida a lo elocuente;/ y la voz del Bautista* que prudente/ por amor del culpado respondía. / Ya el discreto fervor, ${ }^{*}$ que discurría / en siglo de agudezas floreciente, / murió sin enfermar;* no velozmente, / porque de arder y no abrasar muría. / Mereció al alabar ser alabado, / y nunca al reprender fue reprendido; / cuando, no obedecido, fue admirado. / Y por más venerado que creído, / viéndose adolecer de no escuchado, / misterioso murió de mal oído». Y Francisco de Cárdenas escribió otro, que suena así: «Veloz dolencia arrebató la vida/ de la virtud más útil:* en la muerte / cual hombre delinquiendo se divierte, / muriendo ansí quien de pecar se olvida. / Si su elocuencia santa fuera oída, / acaso suspendiera el golpe fuerte, / porque eficacia, ${ }^{*}$ que aun mi error convierte, / a la muerte dexara convencida. / Fue al justo aliento, al divertido espanto, / fue aumento de retóricos primores, / mas admitidos en virtud del llanto. / Fue el último sermón de los mejores; / pues presuroso el fallecer de un santo / es para amedrantar los pecadores». Poco después, Caramuel recuerda la eficacia de la predicación de Nicolás Bautista, ya que el mismo rey le escuchaba con placer, y solía afirmar: «Santo hombre es Nicolás: no le oigo vez ninguna que no saque deseos de ser bueno» (ibidem). 
Quid est mundus? Sincera \& numerosa synodus concionatorum. Coeli enarrant gloriam Dei, \& opera manuum eius adnunciat firmamentum. Dies diei eructat verbum, \& nox nocti indicat scientiam. Concionantur sydera, praedicant elementa. Et in terra non est arbos quae taceat; non est flos qui non reboet hominem, ut florem, suboriri \& marcescere, \& gloriae non Apriles sed Ephemerides enumerare ${ }^{52}$.

El mundo, obra de Dios, predica. También puede hacerlo, por lo menos en parte, el Primus Calamus, obra del hombre. Predican diferentemente, pero predican, y cada uno usa de su retórica. 